\title{
Effect of spatial variability of ground motion on non-linear dynamic behavior of cable stayed bridges
}

\author{
Mouloud Ouanani ${ }^{1,2}$, Boualem Tiliouine ${ }^{2}$ and Malek Hammoutene ${ }^{2}$ \\ ${ }^{1}$ Djelfa University, Faculté des Sciences et de la Technologie, Route de Moudjbara, 17000 Djelfa, Algeria \\ ${ }^{2}$ Ecole Nationale Polytechnique, Civil Engineering Department, Laboratory of Earthquake Engineering and Structural \\ Dynamics, 10 Avenue des Frères Oudek, Hassen Badi, BP. 182, 16200, El Harrach, Algiers, Algeria.
}

\begin{abstract}
This present paper summarizes the main results of incoherence of Spatial Variability of Ground Motion (SVGM) component on the non-linear dynamic behavior of a Mila cable stayed bridge. The Hindy and Novack coherence model is developed for the present study in order to examine the SVGM on bridge responses, Nonlinear bridge responses are investigated in terms of transverse displacements and bending moments along the superstructure and substructure of the study bridge, as well as temporal variations of rotational ductility demands at the bridge piers ends under the incoherence SVGM component. The results are systematically compared with those obtained assuming uniform ground motion. As a general trend, it may be concluded that incoherence component of SVGM should be considered for the earthquake response assessments of cable-stayed bridges.
\end{abstract}

\section{Introduction}

Cable stayed bridges represent long structures of economic and strategic importance. Analysis of the seismic responses of cable stayed bridges cannot be based on the assumption that all base supports of these structures are subjected to uniform earthquake excitation. In general, the ground motions at different points of an area affected by the earthquake are variable in term of intensity and content of frequencies. This variation noted by Spatial Variability of Ground Motions (SVGM), may induce important quasi-static forces in the extended structures when compared to the case of uniform ground motions. The SVGM is characterized by the coherency function which is mainly represented by four components i) incoherence, ii) wave-passage, iii) site-response and iv attenuation effect. In general, the latter is neglected for long extended structures (e.g. bridges, pipelines).

Many researchers have investigated the response of long span structures under non uniform seismic excitations. Most of them have used relatively simple models of simple and continuous beams (e.g. [2, 3]). More realistic bridge configurations were also studied by various researchers (see e.g. references [4,5]). It was found that the structural response increased substantially when using differential support ground motion, especially for more rigid bridges and bridges with supports on different local soil conditions [6,7]. In reference [7], It was concluded that the effect of spatially varying site conditions on seismic response of cable stayed bridge structures is in general more pronounced than that of uniform earthquake motions. It was found that uniform excitations are generally unacceptable for long-span bridges. In reference [8] the seismic responses of a skewed highway bridge under both spatially variable and identical ground motions using both linear and nonlinear time history analyses have been examined. It was concluded that identical ground motions may predict much lower seismic demands on the bridge than spatially variable ones

In this paper, the main results of a numerical investigations of the Hindy and Novack coherence model component of SVGM on non-linear dynamic behavior of a cable stayed bridge are presented. Nonlinear bridge responses are investigated in terms of transverse displacements and bending moments along the superstructure and substructure of the study bridge, as well as temporal variations of rotational ductility demands at the bridge piers ends under the incoherence SVGM component. The results are systematically compared with those obtained assuming uniform ground motion. Finally, based on the numerical results obtained in the present study, conclusions of engineering significance are given. 


\section{Physical and Nonlinear analytical models of bridge structure}

The Mila cable stayed bridge of strategic importance is to be built in order to connect the downtowns of Jijel and Mila (North Eastern Algeria) and has an overall length of $502 \mathrm{~m}$ and consists of three continuous spans in prestressed concrete with a mid-span length of $280 \mathrm{~m}$ and two end spans of $111 \mathrm{~m}$ length each as indicated in Fig. 1(a). The superstructure consists of a longitudinally R.C. deck, 13.30m wide with constant height, (see Fig. 1(b)). The bridge is supported by two $\mathrm{H}$ shaped concrete towers, double plane semi-harp-type cables and two abutments. The two intermediate towers of heights equal to $111.85 \mathrm{~m}$ and $142.85 \mathrm{~m}$ have identical hollow circular cross sections (see Fig. 1(c)). Normal Rubber (N.R.) bearings are located only at right abutment.

In order to include the SVGM effects on the responses of an asymmetric Mila cable stayed bridge, a 3-D FEM model is developed using a small discrete 3-D frame elements for modeling the pylons and the bridge deck and truss elements for the cables modeling. Each adjacent element is connected by a node and at each node six degrees of freedom are considered. The optimal mesh of finite elements of numerical model of the study bridge being obtained based on optimization criteria of the mesh in finite elements [9]. The uncracked section properties are used in the nonlinear model for the bridge piers and their effective torsional moments are determined as $0.2 \mathrm{~J}_{\mathrm{g}}$ [10], where $\mathbf{J}_{\mathrm{g}}$ is the torsional moment of inertia of the pier gross section.

The physical and mechanical properties of the components of the study bridge are listed in Table 1 .

Table 1. Physical and Mechanical properties of the Mila bridge components

\begin{tabular}{|l|l|l|}
\hline Materials & $\begin{array}{l}\text { Deck, piers and } \\
\text { stiffening } \\
\text { girder }\end{array}$ & Stays \\
\hline $\begin{array}{l}\text { Weight density, }(\boldsymbol{\rho}), \\
\text { KN/m }\end{array}$ & 25 & 80 \\
\hline Poisson's ratio, $(\boldsymbol{v})$ & 0.20 & 0.3 \\
\hline $\begin{array}{l}\text { Modulus of elasticity }(\boldsymbol{E}) \\
\text { KN/m }\end{array}$ & $3.9 \times 10^{7}$ & $1.95 \times 10^{8}$ \\
\hline Tensile stress, $(\boldsymbol{\sigma}), \mathbf{K N} / \mathbf{m}^{\mathbf{2}}$ & & $1.24 \times 10^{6}$ \\
\hline $\begin{array}{l}\text { Equivalent } \mathbf{m o d u l u s ~ o f} \\
\text { elasticity },\left(\boldsymbol{E}_{\boldsymbol{e q}}\right) \mathbf{K N} / \mathbf{m}^{2}\end{array}$ & & $1.94 \times 10^{8}$ \\
\hline
\end{tabular}

Following Priestley et al. [10], the bi-linear spring element moment-rotation properties were based on the yield moment-rotation $\left(\mathrm{M}_{\mathrm{y}}, \theta_{\mathrm{y}}\right)$ and ultimate momentrotation $\left(\mathrm{M}_{\mathrm{u}}, \theta_{\mathrm{u}}\right)$ of the pier at the plastic hinge location are obtained from the moment-rotation analysis of the column section based on the moment-curvature relationship (see Fig. 2). The FE software package [11] was used to determine the moment-curvature of the sections of bridge piers. Analysis results are presented in Figs. 2.

The nonlinear analytical model of Mila cable-stayed bridge under SVGM is approximated by the 3-D FEM model (see Fig. 1(a)).

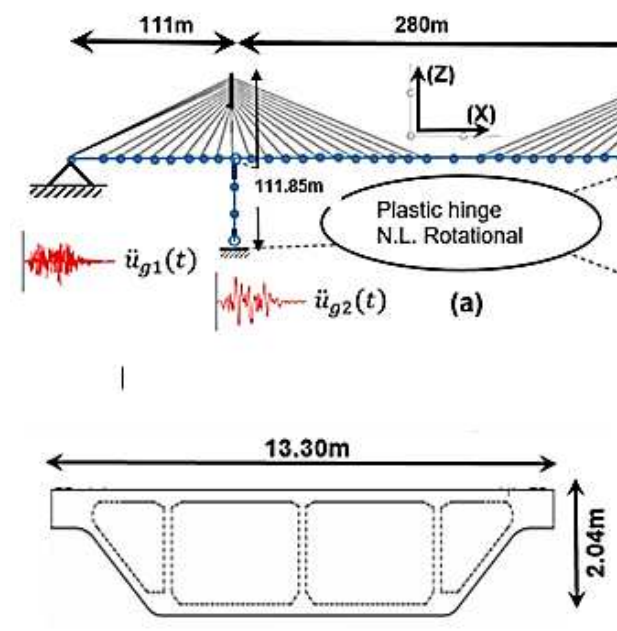

(b)

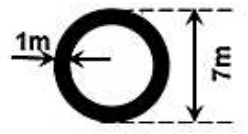

(c)
Fig. 1. Description of bridge: (a) Nonlinear analytical model of Mila cable-stayed bridge, (b) Cross-section of segments, (c) Cross-section of pier.

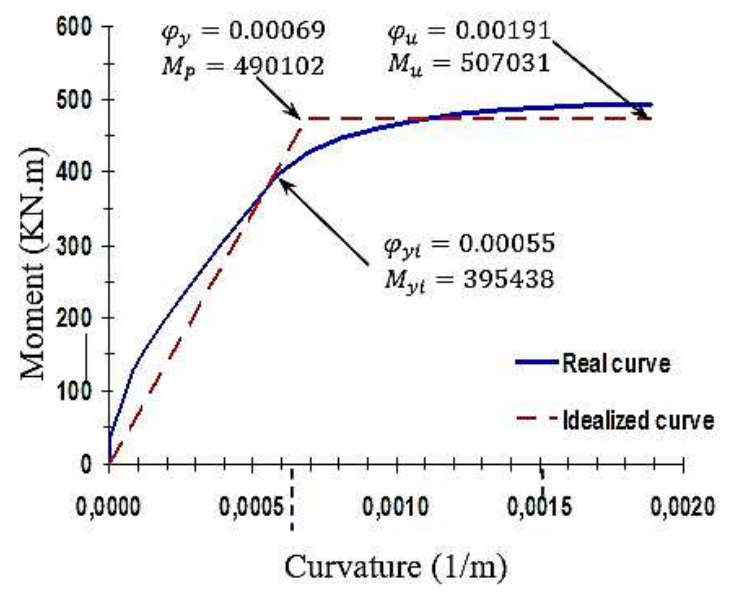

Fig. 2. Pier section analysis results, (a) Moment-curvature curve, (b) $\mathrm{P}-\mathrm{M}$ interaction diagram

\section{Spatially varying ground motion simulation}

The power spectral density of a ground motion is a distinctive characteristic of the ground motion. The Clough et Penzien [12] power spectral density of ground acceleration is given by:

$S_{\ddot{u}_{g}}(\omega)=S_{0} \times H_{g}(\omega) \times H_{f}(\omega)$

Where,

$H_{g}(\omega)=\frac{1+4 \xi_{g}^{2}\left(\frac{\omega}{\omega_{g}}\right)^{2}}{\left[1-\left(\frac{\omega}{\omega_{g}}\right)^{2}\right]^{2}+4 \xi_{g}^{2}\left(\frac{\omega}{\omega_{g}}\right)^{2}}$ 


$$
=\frac{H_{f}(\omega)}{\left[1-\left(\frac{\omega}{\omega_{f}}\right)^{2}\right]^{2}+4 \zeta_{f}^{2}\left(\frac{\omega}{\omega_{f}}\right)^{2}}
$$

where $S_{0}$ is a scale factor, $\omega_{g}$ and $\xi_{g}$ are the first filter parameters and $\omega_{f}$ and $\xi_{f}$ are the second filter parameters.

The Spatial Variability of Earthquake Ground Motion (SVGM) is characterized, among others, by the coherency function, which is mainly represented by three main components: incoherence, wave-passage and siteresponse. Der Kiureghian [13] proposed a general model of spatial seismic coherency function in the following form:

$$
\gamma_{k l}\left(i \omega, \xi_{k l}\right)=\gamma_{k l}\left(\omega, \xi_{k l}\right)^{\mathrm{i}} \times \gamma_{k l}\left(i \omega, \xi_{k l}\right)^{\mathrm{w}} \times \gamma_{k l}\left(i \omega, \xi_{k l}\right)^{\mathrm{s}}
$$

where $\gamma_{k l}\left(\omega, \xi_{k l}\right)^{\mathrm{i}}, \gamma_{k l}\left(i \omega, \xi_{k l}\right)^{\mathrm{w}}$ and $\gamma_{k l}\left(i \omega, \xi_{k l}\right)^{\mathrm{s}}$ characterize the incoherence, wave-passage and siteresponse effects, respectively.

The model expressed by Hindy and Novack [14] is used in the present study for incoherency component.

$\gamma_{k l}\left(\omega, \xi_{k l}\right)^{\mathrm{i}}=e^{-\left(\alpha \omega \xi_{k l}\right)^{\beta}}$

In which $\alpha$ and $\beta$ are dimensionless model parameters and $\xi_{k l}$ denote the separation distance between two stations $\mathrm{k}$ and $\mathrm{l}$. The model parameters are calibrated to the coherency function computed from simulated ground motion corresponding to the zone IIa earthquake of North Eastern Algeria. Fig. 3 presents the exponential decay of the Hindy and Novack model with frequency along the deck of Mila cable stayed bridge at separation distances of 110,391 and $502 \mathrm{~m}$ for regression parameters, $\alpha=5.87 \times 10^{-5}$ and $\beta=1.52$ suggested by [15].

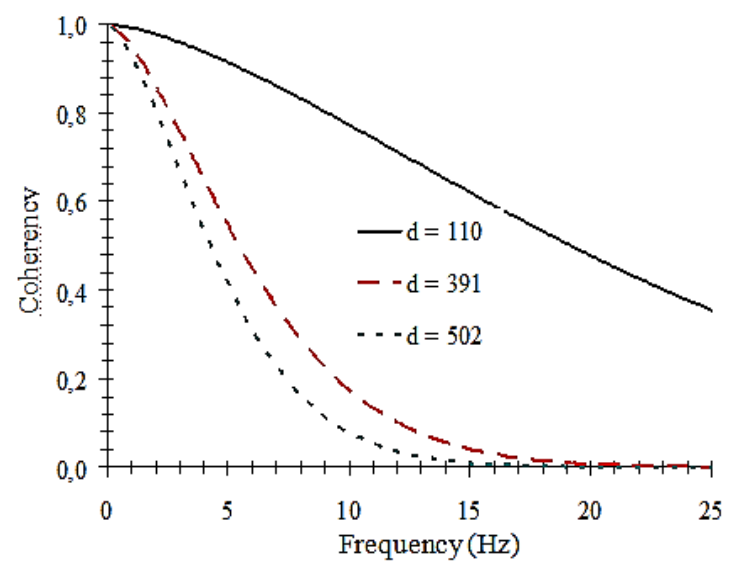

Fig. 3. Variation of coherency models with frequency at separation distances of 110, 391, and $502 \mathrm{~m}$.

\section{Numerical results and discussion}

In order to further assess the Hindy and Novack coherence model of SVGM component on nonlinear seismic responses of a study, the referential simulated earthquake accelerogram is applied to the left of abutment considered herein as the epicenter of the earthquake and compatible with prescribed scaled to peak acceleration $0.275 \mathrm{~g}$ supposed equivalent to soil type $S_{2}$ (firm site condition) as described in [16].

Nonlinear bridge responses are investigated in terms of transverse displacements and bending moments along the superstructure and substructure of the study bridge, as well as temporal variations of rotational ductility demands at the bridge piers ends under the incoherence SVGM component are evaluated for the study bridge using Newmark direct time integration method with parameters $\alpha=0.5$ and $\beta=0.25$ (i.e. using the unconditionally stable average acceleration method). In this study, the two seismic excitation scenarios are simulated:

1) Uniform ground motion characterized by no time delay $\left(\mathrm{v}_{\mathrm{app}}=\infty\right)$, no loss of coherence $(\alpha=0)$ and two seat type abutments and the piers are founded on the soil supposed equivalent to soil type $S_{2}$ (firm site) in accordance with RPOA [2008] respectively.

2) Only the incoherence effect is considered, the time histories applied are correlated $(\alpha=5.87 \times$ $10^{-5}$ and $\beta=1.52$ ). Two seat type abutments and the piers are founded on firm site of type $S_{2}$ in accordance with RPOA [2008]ely.

\subsection{Influence of incoherence effect on absolute maximum seismic responses along the deck}

Fig.4 illustrates the variation of absolute maximum vertical displacements and bending moments along the deck of the Mila bridge under uniform ground motion and the Hindy and Novack coherence model of SVGM component.

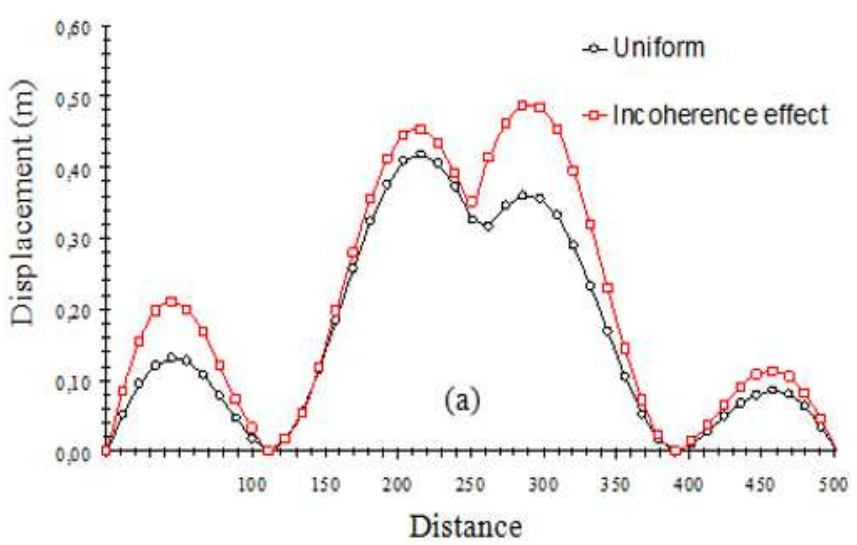




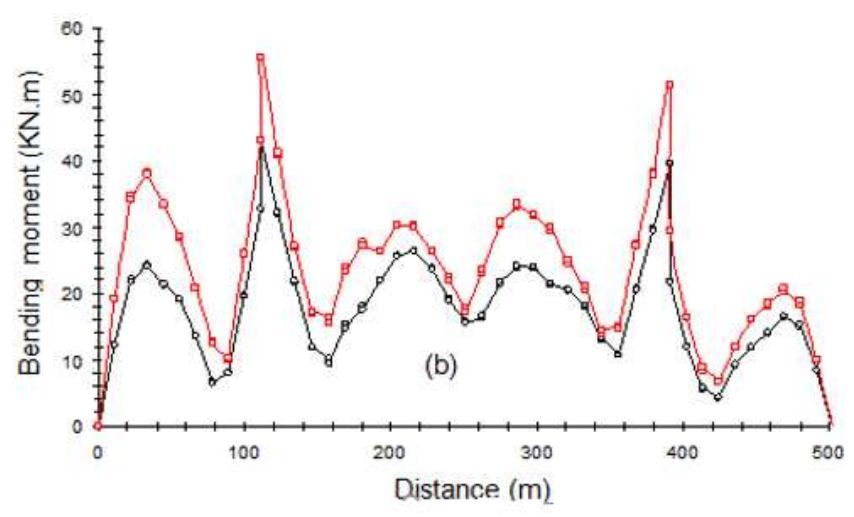

Fig. 4. Absolute maximum seismic responses along the deck of Mila cable-stayed bridge, (a) Vertical displacement, (b) bending moments

From Fig. 4(a) it is clearly seen that, the absolute maximum vertical displacement along the deck of Mila cable stayed bridge induced by incoherence effect are more pronounced than those calculated by the identical seismic excitations. For illustration, the uniform ground motion develops the maximum deck displacement at midcentral span equal to 0.42 , which corresponds to significant decreases of more than $14 \%$ respectively when the incoherence effects is considered. It is also observed from Fig. 4(b) that the bending moments along the deck are maximums at section on the short pier, large bending moments are obtained along the deck when the incoherence effect is considered. The latter induced a maximum bending moment equal to $55643 \mathrm{KN}$.m, while it is equal to $43087 \mathrm{KN}$ when the uniform ground motion is considered.

It is clear for the studied case, the identical seismic excitation model generally produces the lower responses that the uniform ground motion..

\subsection{Influence of incoherence effect on absolute maximum seismic responses on pier heights}

Figs 5.1 and 5.2 depict the variation of absolute maximum horizontal displacements and bending moments on height of short and tall piers of the Mila cable stayed bridge under uniform ground motion and the Hindy and Novack coherence model of SVGM component.

From Figs. 5.1(a) and 5.1(b) it is clearly seen that, the absolute maximum longitudinal displacements on short and tall towers height of Mila cable stayed bridge are relatively close to each other which corresponds to rigid movement of deck. It is also observed that the incoherence effect induces large values of displacements on towers height in comparison with uniform seismic excitations. For illustration, the maximum deck longitudinal displacement at top of tall tower equal to $0.47 \mathrm{~m}$ for uniform excitation which is amplified of more than $38 \%$, when the incoherence effect is considered.

It is also observed from the Figs. 5.2(a) and 5.2(b) that the maximum bending moments are maximums at the short pier for uniform ground motions and incoherence effect, very large bending moments values are obtained on tower when the incoherence effect is considered, inducing a maximum bending moment equal to $467447 \mathrm{KN} . \mathrm{m}$, while it is equal to $381004 \mathrm{KN}$.m when the uniform ground motion is considered (i.e a substantial reduction of over $18 \%$ ).
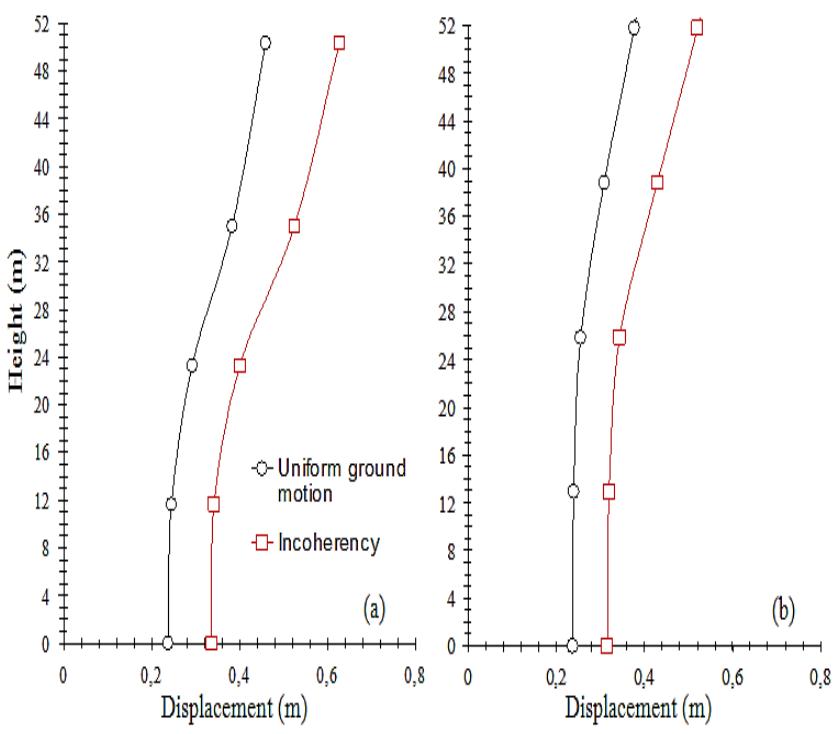

Fig. 5.1. Absolute maximum horizontal displacements, (a) short pier, (b) tall pier

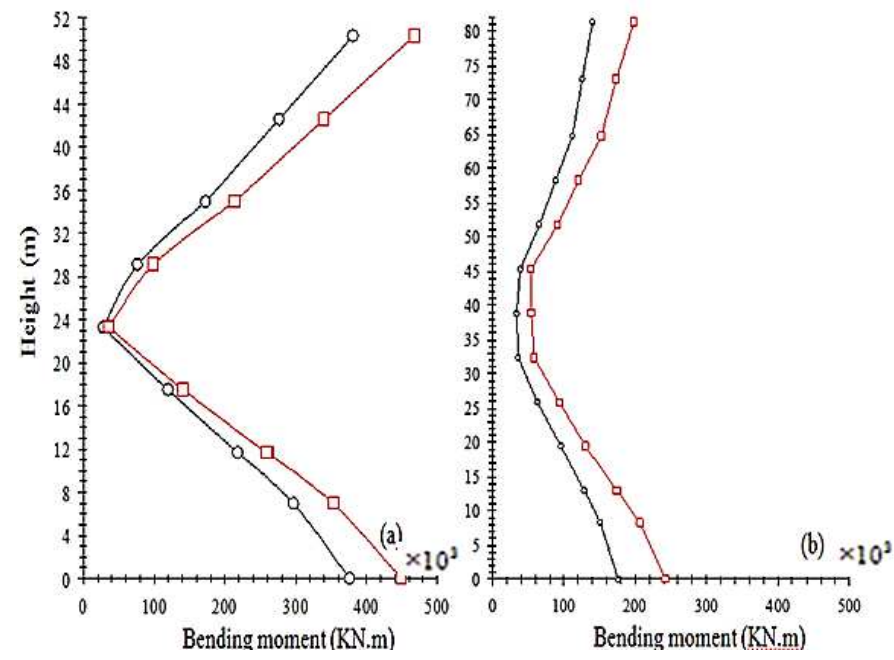

Fig. 5.2. Absolute maximum bending moments, (a) short pier, (b) tall pier.

\subsection{Influence of SVGM on rotational ductility demands at pier ends of bridge}

Figs. 6.1 and 6.2, below shows the temporal variations in longitudinal direction of rotational ductility demands at short and tall pier ends under uniform ground motions and incoherence effect. 

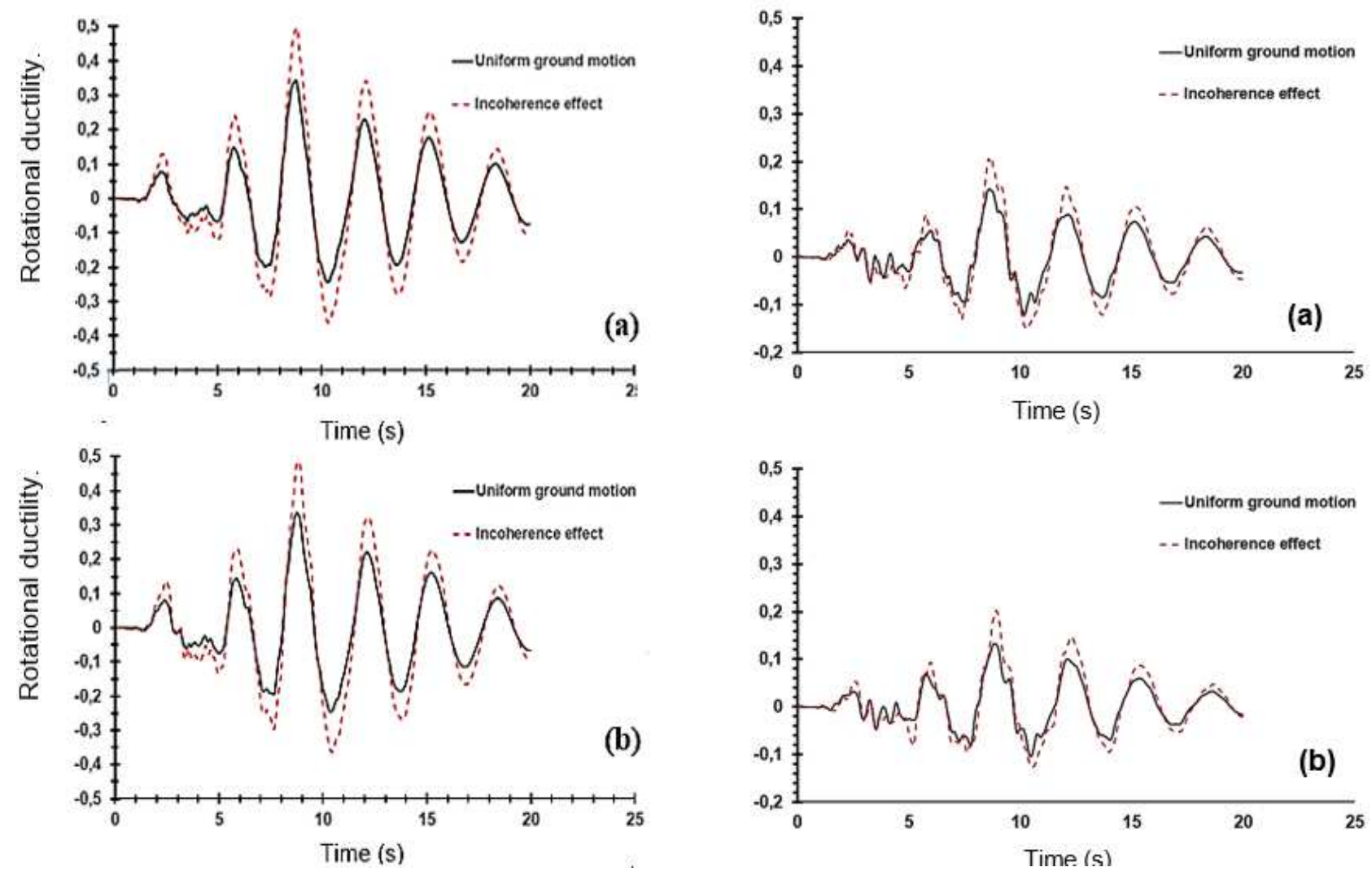

Fig. 6.1. Rotational ductility demands at short pier under uniform ground motions and incoherence effect, (a) Bottom of short pier, (b) Top of short pier.

It is noted from Figs. 6.1 and 6.2 that rotational ductility demands at short pier are more important than the tall pier. It is also observed, that the incoherence effect develops rotational ductility demands more important than uniform ground motions. On the other hand, it is clearly seen from Figs. 6.1 and 6.2 that the rotational ductility demands at bottom and top of short and tall piers are well below of elastic ductility limits state and that therefore no damage is likely to occur at the ends of the piers.

As a general trend, it may be concluded that nonlinear analytical models used in the seismic responses of bridge explicitly consider the incoherence effect of SVGM component.

\section{CONCLUSION}

In this this study, 3-D FEM model of the Mila cable stayed bridge is performed and comparative assessments of the non-linear dynamic behavior of study bridge under incoherence effect and uniform ground motions are presented. Nonlinear bridge response quantities are discussed in terms of displacements and bending moments along the deck and the piers heights of the study bridge as well as temporal variations of rotational ductility demands at the bridge piers ends under incoherence effect and uniform ground motions are

Figure 6.2. Rotational ductility demands at tall pier under uniform ground motions and incoherence effect, (a) Bottom of tall pier, (b) Top of tall

evaluated in order to investigate the effect of spatial variability of earthquake ground motion on non-linear dynamic behavior of a Mila cable stayed bridge

From the results obtained in this investigation, the following general conclusions can be drawn:

- Numerical results show clearly the importance of incoherency effect on the seismic response of cable stayed bridge structures.

- The effect of incoherency on seismic response of cable stayed bridge is in general more pronounced than those of excitation ground motion.

- The rotational ductility demands at the bridge piers are more pronounced in the short piers than in the tall piers regardless of the earthquake ground motion model used uniform ground motions and incoherency effect.

- Particularly attention should also be given to higher seismic ductility demands induced in the short piers under incoherency effect that may exceed the rotational ductility limits of piers resulting eventually in global bridge collapse.

\section{References}

1 A. Der Kiureghian, A. Neuenhofer, Response spectrum method for multi-support seismic 
excitations, Earthquake Engineering and Structural Dynamics, 21(1992)

2 A. Zerva, AHS. Ang, YK Wen, Study of seismic ground motion for lifeline response analysis, Civil Engineering Studies, Structural Research Series, University of Illinois.

3 A. Zerva, Response of multi-span beams to spatially incoherent seismic ground motions, Earthquake Eng. Struct. Dyn., 19(1990)

4 RS. Harichandran, W. Wang, Response of indeterminate two span beam to spatially varying seismic excitation, Earthquake Eng. Struct. Dyn. 19(1990)

5 V. Simeonov, G. Mylonakis, A. Reinhorn, I. Buckle, Implications of spatial variation of ground motion on the seismic response of bridges: Case study', Proc.FHWA/NCEER Workshop on the National Representation of Seismic Motion, Tech. Rept, 970010; NY, (1997)

6 A. Der Kiureghian, P. Keshishian, Effects of incoherence, wave passage and spatially varying site conditions on bridge response, Proc. FHWA/NCEER., Report NCEER-97-0010, National Center for Earthquake Engineering Research, New York, (1997)

7 M. Ouanani, B. Tiliouine, M. Hamoutene, The nonlinear dynamic behavior of cable stayed bridges under spatial variability of earthquake ground motion, $2^{\text {nd }}$ International Conference on Material and Structural Mechanics - MSM (2016) ground motions on the seismic response of a multispan bridge, Soil Dyn. Earthqu. Eng. 25(2005)
9 B. Tiliouine, M. Ouanani, Réponse Sismique 3-D d'un Pont-Caisson à Inertie Variable, Proceedings of the $8^{\text {th }}$ French National Conference on Earthquake Engineering: Dynamic and Vibratory Aspects in Civil Engineering, AFPS Paris, France (2011)

10 M. J. N. Priestley, G. Calvi, M.J. Kowalsky, Displacement-based seismic design of structures, Pavia: IUSS Press, M.

11 CSI, Bridge, Computer and Structures. Inc. SAP2000 (Nonlinear version 15), Nonlinear User's Manual Reference, Berkeley, CA, USA (2012)

12 R. Clough, J. Penzien, Dynamics of structures, Computers and Structures, Inc., Berkeley, USA (1995).

13 A. Der Kiureghian, A coherency model for spatially varying ground motions, Earthquake Engineering and Structural Dynamics, 25(1996)

14 A. Hindy, M. Novak, Pipeline response to random ground motion, J Eng Mech ASCE, 106(1980)

15 K. AfifChaouch, B. Tiliouine, M. Hammoutene, R. Sigbjornsson R. Rupakhety, Estimating ground motion incoherence through finite source simulation: a case study of the 1980 El-Asnam, Earthquake, Bull Earthquake Eng, 14(2016)

16 RPOA (2008). Partie I: Ponts, Règlement Parasismiques Applicables au Domaine des Ouvrages d'Arts, Algeria. 